\title{
6
}

\section{OBRAS ESENCIALES DE M.A.K. HALLIDAY}

\section{Elsa Ghio, Federico Navarro y Annabelle Lukin (comps.)} $1^{\text {a }}$ ed. Santa Fe: Ediciones UNL. CABA: Eudeba, 2017. 364 pp. ISBN 978-987-749-096-1

Ofelia Zanetta

Las Obras Esenciales de M.A.K. Halliday es una compilación de trabajos traducidos al español que posibilita a toda la comunidad hispano-parlante aproximarse a la cosmovisión sobre el lenguaje que tiene uno de los lingüistas más relevantes de los últimos tiempos, el británico Michael Halliday. Este volumen recorre los nudos teóricos más importantes de la teoría Lingüística Sistémica Funcional (LSF de aquí en más), y abre nuevas oportunidades de difusión y análisis de una teoría general del lenguaje que problematiza la relación de éste con la construcción/ percepción del mundo por parte de los hablantes.

El recorrido que proponen los editores Elsa Ghio, Federico Navarro y Annabelle Lukin se organiza en tres momentos. El primero de carácter introductorio, abre con un 1. «Prefacio» escrito por el mismo Halliday, lo último que ha publicado, en el cual expresa que ha desarrollado una teoría «aplicable» que puede ponerse en práctica para responder a problemas y demandas de la vida real (Halliday; 2017:9). Este principio direcciona la selección de los materiales traducidos, pues en cada uno de éstos se problematiza un aspecto de la praxis humana en su relación con el sistema lingüístico. A continuación, los editores Ghio, Navarro y Lukin relatan en el 2. "Prólogo a las Obras Esenciales de M.A.K. Halliday» que surgió esta iniciativa para dar respuesta a la necesidad de contar con materiales 
teóricos de la LSF en español y así posibilitar su acceso a estudiantes y a la comunidad académica en general. Este apartado se cierra con el capítulo 3. «M.A.K Halliday: de la opción al recurso, de la gramática al registro» de Salvio Martin Menéndez, quien caracteriza y explica las categorías pilares de esta perspectiva lingüística: significado, opción, registro, e historiza brevemente los fundamentos teóricos sobre los que se funda. Menéndez propone una puerta de entrada clara y precisa a los postulados de la LSF. Además, hace un racconto sobre cómo Beatriz Lavandera, su maestra, es la primera catedrática que introduce y propone una aplicación de la teoría de Halliday y Hassan para la descripción de los textos en nuestro contexto local. Su rol como docente e investigadora posibilitó la difusión y el diálogo de la LSF con el análisis del discurso en nuestro país, como así también, la formación de lingüistas en esta línea como el mismo Menéndez.

El segundo momento propuesto por los editores, "Obras esenciales», es la traducción de un corpus de nueve trabajos: 1. «De la inefabilidad de las categorías gramaticales», 2. «Cómo significas?», 3.«Algunos rasgos lexicogramaticales del texto de Crecimiento Poblacional Cero», 4. «Ideas sobre el lenguaje», 5. «Nuevas formas de significar: un desafío para la lingüística aplicada», 6. «Sobre la «arquitectura» del lenguaje humano», 7. «Hacia una teoría del aprendizaje basada en el lenguaje», 8. "Sobre la gramática del dolor» y 9. «Sobre el concepto de «lingüística educativa»». La traducción de éstos ha estado a cargo de lingüistas especialistas en LSF que han formado estudiantes en esta línea y producido valiosas investigaciones, por lo que este volumen tiene un nivel de especificidad y claridad teórica que lo vuelve aún más valioso como aporte al campo de los estudios lingüísticos en español. Los artículos seleccionados proponen un recorrido que abarca varias décadas del trabajo de Halliday y en éstos se explican los fundamentos teóricos de la LSF, su concepción de lenguaje, la relevancia de la gramática en la construcción de significados, se presenta el análisis y aplicaciones a los textos y aportes de esta teoría en el campo de la educación, entre otros temas que se abordan.

La presente reseña propone reagrupar en torno a tres ejes temáticos el cuerpo de traducciones: un eje meta-teórico, un eje sobre la aplicación de la LSF a los textos y un último eje sobre la relación lenguaje-aprendizaje. Este abordaje en la descripción de los artículos proporciona un recorrido más claro y cohesivo de los principales tópicos que se desarrollan en el volumen y también, un mejor acceso 
para el lector nobel en LSF. En el primer eje meta-teórico se agrupan los trabajos que analizan y reflexionan sobre la posibilidad real de estudiar el lenguaje como objeto de estudio, desde una descripción y un razonamiento que instrumenta el propio lenguaje. Introduce este eje el artículo traducido por Jorge Arús Hita en el capítulo 1. "De la inefabilidad de las categorías gramaticales», en éste se presenta la complejidad de objetivar el lenguaje mediante categorías lingüísticas, es por esto que la pregunta que recorre estas páginas es hasta qué punto un metalenguaje es posible para el estudio de las categorías gramaticales, ya que la riqueza del lenguaje natural implica limitaciones en su habilidad para interpretarse a sí mismo. Continúa con esta línea de trabajo el capítulo 2. «¿Cómo significas?» traducido por Muriel Picone, en el que Halliday explica:

Si el significado surge del impacto entre lo consciente y lo material como formas de la experiencia mutuamente contradictorias, entonces no es sorprendente que, cuando la experiencia se interpreta semánticamente, estos dos tipos de proceso, el material y el consciente, se diferencien semánticamente. Pero hay una vuelta de tuerca más. El proceso semiogenético, como hemos visto, supone el establecimiento de una relación entre sistemas, de modo tal que uno es la realización del otro - es decir, mantienen una relación de Instancia (Token) y Valor (Value). Esta relación Instancia-Valor se establece en ambas interfaces, y es lo que hace posible separarlas e insertar una gramática entre ellas. Aquí entonces nos encontramos con el tercer tipo de proceso definido por la gramática: el proceso relacional, basado en la identificación de una Instancia con un Valor. La gramática del lenguaje natural, en su metafunción ideacional, es una teoría de la experiencia humana; por esta razón, es razonable pensar que tomará como punto de partida el mismo conjunto de contrastes del que, básicamente, su propio potencial se deriva (2017:71).

El segundo eje del cuerpo de traducciones profundiza la propuesta teórica de la LSF como una lingüística aplicada. Estos capítulos se focalizan en desarrollar los nodos centrales de esta teoría del lenguaje para argumentar su articulación con el contexto socio-semiótico. Así, en el capítulo 3. «Algunos rasgos lexicogramaticales del texto de Crecimiento Poblacional Cero» traducido por Analía Kevorkian, Verónica Piaggio y Federico Navarro, se muestra la aplicación de la gramática sistémica al análisis e interpretación del texto «Crecimiento Poblacional 
Cero». Se divide en siete secciones en las cuales Halliday reflexiona y realiza breves comentarios evaluativos sobre: el tema, la estructura de la información, el modo y la modalidad, la transitividad, los complejos clausales, la cohesión lexical, la nominalización y la metáfora gramatical. Halliday intenta mostrar la gramática que opera al interior del texto para construir significados, ya que cada rasgo que exhibe el texto se plantea en el contexto de otras opciones. En el capítulo 4. «Ideas sobre el lenguaje» traducido por Federico Navarro, es una invitación a volver a pensar en el lenguaje como un recurso y no desde las taxonomías aprendidas en el sistema escolar que lo vuelven sólo una regla. Según Halliday se puede identificar dos imágenes del lenguaje: desde una visión filosófico-lógica, cuya orientación es normativa, representa el lenguaje como regla y se centra en el análisis formal de oraciones. Y, una visión descriptivo-etnográfica, su orientación es descriptiva, presenta al lenguaje como un sistema de opciones y enfatiza la interpretación semántica del discurso. Halliday subraya cómo estas ideas sobre el lenguaje atraviesan la historia del individuo que siendo un niño ve al lenguaje como un potencial para pensar y construir su imagen de realidad y luego, al entrar al sistema educativo, cambia y lo ve como un conjunto de reglas y categorías como: sustantivo, oración, etc. Finaliza con el planteo de que el valor de la interpretación semiótica es que nos muestra cómo se estructura el mundo de los significados, y cuáles son sus constantes (2017:134) y que uno como adulto es esperable que tenga más apertura sobre las ideas sobre el lenguaje y la importancia de ayudar al niño a aprender a significar.

El siguiente capítulo se llama 5. «Nuevas formas de significar: un desafío para la lingüística aplicada» cuya traducción estuvo a cargo de Elsa Ghio. Se narra cómo, con el paso de los años, la disciplina lingüística aplicada ha planteado nuevos desarrollos teóricos; no obstante, su nuevo reto es comprender de qué manera funciona la gramática como una teoría de la experiencia (Halliday; 2017:149). Esto viabiliza hondar en el estudio de problemáticas sociales: el sexismo, la otredad racial, las desigualdades sociales, etc.; debido a que es en el empleo de los recursos que ofrece la lengua en donde se cimientan estas formas de construir la realidad. El capítulo 6. "Sobre la "arquitectura" del lenguaje humano» traducido por Annabelle Lukin y Elsa Ghio es una introducción que escribe M.A.K. Halliday a sus obras completas. Presenta y explica los conceptos básicos que sostiene sobre el lenguaje: la lengua como un sistema semiótico, los tipos de complejidad en el 
lenguaje, la dimensión paradigmática, la estratificación, entre otros; mediante el desarrollo de estas categorías el lingüista delinea la naturaleza multidimensional de la experiencia humana que se proyecta en el lenguaje y ratifica que, si los modos de interactuar con el contexto social son complejos, el análisis de esta interacción también lo es. Finalmente, el último trabajo que decidimos incluir en este segundo eje sobre la aplicación de la LSF a los textos, es el artículo 8. «Sobre la gramática del dolor» traducido por Alicia Noceti. Este trabajo refiere a los diferentes modos de significar la experiencia humana, específicamente: el dolor. Halliday ilustra cómo los hablantes representamos nuestra cotidianeidad optando, dentro del sistema de la lengua, por el dolor como una cosa, como un atributo y o/ como un proceso, según el modo que nos resulte más significativo. Independientemente de la opción elegida, es la gramática mediante la cual nuestro mundo toma forma; por esto, el teórico, resume que cuando se estudia la gramática de la vida cotidiana ...estamos tratando de comprender la construcción subyacente a la experiencia humana (Halliday; 2017:278).

El tercer eje del cuerpo de traducciones, según nuestra propuesta de lectura, versa sobre uno de los lineamientos más productivos que ha tenido esta lingüística aplicada, su interés por el estudio de la relación lenguaje-aprendizaje. El artículo 7. «Hacia una teoría del aprendizaje basada en el lenguaje» traducido por Fabián Mónaco y Elsa Ghio, refiere a la importancia de aunar el estudio del lenguaje al del aprendizaje. Halliday expone veintiuna características sobre el desarrollo del lenguaje en los niños que, según él, son fundamentales para abordar una teoría del aprendizaje basada en éste. Halliday entiende que aprender es aprender a significar y estudiar esta relación como una continuidad involucra leerlo como un proceso semiótico natural de la especie humana, equiparable a cualquier otra actividad. La traducción del capítulo 9. "Sobre el concepto de "lingüística educativa"» de Fabián Mónaco y Elsa Ghio, cierra este tercer eje. El trabajo completa la mirada de Halliday sobre su concepción de educación-lenguaje, pues especifica lo que se ha entendido por conocimiento educativo a lo largo del siglo XX, en el cual el lenguaje se ha enseñado como un objeto separado de la cultura, privilegiando la enseñanza de la normativa, la gramática y la redacción, por ejemplo, lo que ha redundado en una asignatura sobre el lenguaje ajena a la experiencia de sus protagonistas: los niños. Se concluye con el planteo de que es necesario considerar al lenguaje como punto de partida de cualquier propuesta educativa 
y es el uso de la ciencia de la gramática lo que brinda una mayor comprensión de los procesos de enseñanza y aprendizaje.

El último momento del libro que proponen los editores se titula «Recuentos y entrevistas» y consta de dos trabajos: capítulo 10. «Una mirada retrospectiva sobre la LSF y la alfabetización» traducida por Elsa Ghio y Ann Montemayor-Borsinger, y capítulo 11. «Entrevista con M.A.K. Halliday» a cargo de Geoff Thompson (GT) y Heloisa Collins (HC), traducido por Federico Navarro. Ambos textos son un recorrido en primera persona por la vida y exploraciones teóricas de Halliday en diálogo con su propuesta lingüística y en consonancia con las problemáticas de su tiempo: qué lo llevó a iniciar este largo camino por el lenguaje, qué circunstancias históricas, sociales y políticas influyeron en sus elecciones, qué influencias teóricas marcaron su mirada analítica, la relación de la LSF con otras escuelas lingüísticas, su motivación por estudiar el balance entre lo material y lo semiótico en la historia humana (Halliday; 2017:338), la lingüística y la cognición como perspectivas futuras, la lingüística crítica y su abordaje de los aspectos políticos, el concepto de registro, la discusión sobre la utilidad del concepto de género y la complejidad de la marcación del tema, etc. Ambas traducciones argumentan la relevancia y la potencialidad de una lingüística aplicada que avanza para dar respuesta a interrogantes de la compleja relación entre lenguaje y sociedad; es por esto que la LSF es una de las teorías del lenguaje que más desarrollo ha tenido en las últimas décadas y en todo el mundo.

En suma, el volumen aquí reseñado es una compilación que nos invita a conocer y adentrarse en la lingüística sistémico funcional cuya potencialidad reside en su interpretación del lenguaje como un sistema semiótico de opciones que cada hablante pone en tensión cada vez que se comunica. Si bien es necesario avanzar con la traducción de más trabajos de la LSF en los que se profundiza la categoría y marcación del tema, el leguaje de la ciencia, la relación del leguaje y la educación, el análisis léxico-gramatical, entre otros; esta propuesta de los compiladores Ghio, Navarro y Lukin es una invaluable contribución a los estudios lingüísticos ya que representa una mirada de conjunto de la obra de Halliday y posibilita a docentes, investigadores y estudiantes contar con materiales en español para proporcionar herramientas de análisis para problemas y discusiones, parafraseando a Halliday, sobre cómo usamos el lenguaje para organizar nuestra visión del mundo (y de nosotros mismos), y para interactuar con nuestro entorno. 